\title{
A Design of the Hot Water Bath System
}

\author{
Yingqing $\mathrm{Wu}$ \\ College of Mechatronics Engineering and Automation, \\ Shanghai University, \\ Shanghai 200072, China
}

\begin{abstract}
The paper designed a method to get hot water by combining heating method composed of solar collector and air source heating pump to change the former situation of environmental pollution and energy wasting brought by original oil-fired boilers. The control system offering user-friendly human machine inter face adopting the framework of PLC + HMI. Through fuzzy control strategy, the system is more stable and energy saving. The heat pump operation strategy is organized based on time-oriented electricity pricing policy. The practice proves that the system can save energy effetely and produce heat on-demand in real-time control.
\end{abstract}

Keywords: Fuzzy control; solar energy Heat pump; Energy-saving.

\section{INTRODUCTION}

At present, most of the large hotels use fuel boiler system to make bath water for customers checked in. Although this method can produce a sufficient amount of water, the heat source is on serious environmental pollution that cannot adapt to the social require of sustainable development.[1] At the same time, considering the current unstable oil price, the hotel will get loss if the price rises suddenly. According to the energy problem of bating hot water system at the present stage, energy saving system that can produce on demand, transport reasonably, realize real-time control and comprehensive optimization has become an urgent demand.

\section{THE DESIGN OF THE SYSTEM STRUCTURE}

This paper uses the solar energy heat collector and the air source heat pump (ASHP) together to get hot bath water. The method has the advantages of high efficiency, energy saving and environmental protection. At the same time, this method makes full use of the difference of peak and valley price and optimizes the heat pump operation strategy to achieve the purpose of saving electricity.

Solar energy as a clean and cheap energy alternative, the advantage is very obvious. The system gives priority to the use of solar collector for heat production. Considering the initial limit of cost and installation space, this system expands the solar collector scales as far as possible to improve energy saving effect. In the process of system design, the demand of hotel bathing hot water should be fully considered. In general, the daily water consumption in winter of hotel for three hundred or four hundred people to stay is about $60 \mathrm{t}$. The average temperature is $55^{\circ} \mathrm{C}$. And eachof the daily water consumption in spring, autumn and summer is about $45 \sim 55 \mathrm{t}$. The average temperature is $55{ }^{\circ} \mathrm{C}$.
Air source heat pump is a device for heat supply using air as heat source. It can lower the energy consumption when changing the thermal energy from low temperature to high temperature. Comparing the method of fuel heating, it has higher energy efficiency. The average coefficient of performance (COP) of the air source heat pump in this paper is 4.6. It can up to 5.7. In winter the lowest is $2.5[2]$.Heat pump and boiler fuel cost comparison is shown in table 1 .

TABLE 1. COST COMPARISON

\begin{tabular}{|l|l|l|}
\hline \multicolumn{1}{|c|}{ Comparison } & \multicolumn{1}{|c|}{ Heat pump } & \multicolumn{1}{c|}{$\begin{array}{c}\text { Fuel oil water } \\
\text { heater }\end{array}$} \\
\hline Energy & Commercial electric & Light diesel oil \\
\hline Energy calorific value & $860[\mathrm{kcal} /(\mathrm{kW} \cdot \mathrm{h})]$ & $10200[\mathrm{kcal} / \mathrm{kg}]$ \\
\hline $\begin{array}{l}\text { Average coefficient of } \\
\text { performance }\end{array}$ & $460 \%$ & $70 \%$ \\
\hline Energy consumption & $8.85[\mathrm{~kW} \cdot \mathrm{h}]$ & $4.9[\mathrm{~kg}]$ \\
\hline Cost & $7.97[\mathrm{yuan}]$ & $24.5[\mathrm{yuan}]$ \\
\hline Environmental impact & Without any pollution & Serious pollution \\
\hline Safety performance & safe & $\begin{array}{l}\text { Potential safety } \\
\text { problems }\end{array}$ \\
\hline
\end{tabular}

In table $1,1000 \mathrm{~kg}$ water of $20^{\circ} \mathrm{C}$ is heated by $35 \mathrm{k}$ under the same condition using air heat pump and fuel oil water heater severally. In this process $35000 \mathrm{kcal}$ heat is needed. The commercial electric price is $0.90 \mathrm{yuan} /(\mathrm{kW} \cdot \mathrm{h})$ and the Light diesel oil price is 5.00 yuan $/ \mathrm{kg}$.

In addition, the air source heat pump also has the advantages of convenient installation, high energy utilization efficiency, the greenhouse effect and environmental protection. Therefore, it is widely applied[3].

When choosing the air source heat pump capacity, we should give full consideration to the user's water needs in hotel and the ability of solar hot water heater production. At the same time, the opening time of heat pump should be less than $16 \mathrm{~h}$ to avoid high price generated at high price electricity time.

The water production of air source heat pump is mainly related with temperature. According to the characteristic curve of Shanghai average temperature reports and heat pump unit, this paper designed 4 units of $77 \mathrm{kw}$ heat water pump. These pumps' input power is $18 \mathrm{kw} * 4$. When the average temperature in Shanghai winter night was 5 degrees, $4.4 \mathrm{t}$ hot water can be produced by 4 sets of $77 \mathrm{~kW}$ heat pump per hour. While in spring and autumn night, the average temperature is 15 degrees. Then the heat pumps can produce $7.2 \mathrm{t}$ hot water per hour. In summer, the average temperature is higher that makes the air source heat pump has a higher COP value, which has strong ability to produce 
hot water. As a result, the hot water need will naturally meet design requirement in summer as long as the need is met in winter, spring and autumn.

In the design process, the solar energy in one day should transforms into heat energy of hot water as much as possible. So it will serve as the production water striker. And the air source heat pump will serve as the main heating device in order to ensure the production of hot water provide for the customer.

When designing the system, water, time of use electricity price and hotel location etc. should be especially considered. So as to properly configure the hot water bath equipment capacity and reasonably compile the energy saving algorithm.

In order to improve the stability of the system, the reliability of information collection for control object must be improved. Therefore, in the design of water level and temperature acquisition mode, three sets of channels is arranged respectively. Each channel is distributed in different areas of water tank to collect the water temperature and level. Specific bathing hot water energy-saving system diagram is shown in figure 1 .

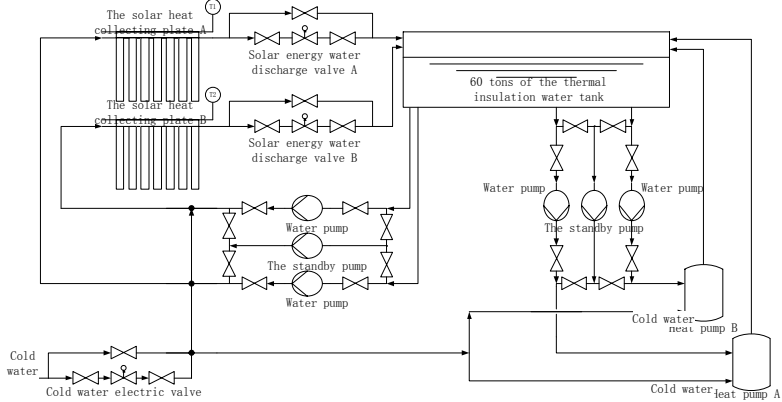

Fig.1. Drawing of system construction

\section{THE HARDWARE DESIGN OF THE CONTROL SYSTEM}

The control part of energy-saving bathing hot water system using Siemens S7-200 series PLC as the main controller. The digital module EM221 is used to output control the start and stop of a variety of valve pump. The analog acquisition module EM231 is used to collect various temperature, level and other analog quantity. At the same time, Siemens man-machine interface equipment TP177B DP PN is used for interactive control of the entire energy-saving bathing hot water system. The hardware structure is shown in figure 2 .

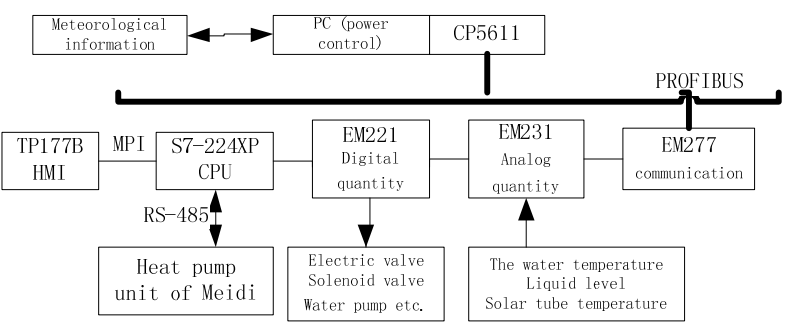

Fig.2. Design of hardware

In the process of system design, module of EM277 is added, so that the system has the Profibus communication ability[4]. At the same time, the Siemens communication card CP5611 is inserted into the host computer and the configuration software(such as the third party's force control software or Siemens WinCC Flexible) is installed. Thus the Siemens PC Access is used to establish an OPC Server in the host computer for a variety of configuration software to remote monitor and control the energy-saving bathing hot water system mounted on the Profibus[5].

The S7-224XP used only has two serial data interfaces. One connect the Siemens man-machine interface equipment through the built-in MPI protocol. The other as a free port, communicates with the heap pump to control the heat pump unit's operation. So when the system is under normal operation, The PLC cannot insert debugging interface for online debugging operation. At this point, EM277 can be used for another purpose to debug PLC program through the Profibus communicated with host computer. In the operation of the system, the host computer gets the next day weather information through internet and then estimates the capacity of the solar energy heat collector of the next day. Then the host computer determines the heat pump's running time during the low electricity price period from evening to morning.

\section{THE SOFTWARE DESIGN FOR ENERGY SAVING}

The software design of energy-saving bathing hot water system mainly include the acquisition and filtering of analog quantity, control of solar heat collector, heat pump's energy-saving operation program for TOU price, operation mode of heat pump based on safety line, comprehensive energy-saving operation mode, historical data record, control and interface program of variety kinds of motor operated valve[6 -9].

Analog acquisition. In order to make the system run in a stable and reliable state, all of the analog quantity acquisition must be authenticity and validity. So the same state quantity gathered distributed in different position is needed to do filter process. That is averaging the new sampling value and the five correct sampling values before. And then analyze the same state data gathered from different position to get the correct system operation state.

\section{A. Solar heat collector water supplement}

The water supplement loop of the solar heat collector adopts single output fuzzy controller with double input. The outlet water tube temperature of solar heat collector, the water temperature of the water tank and water tank liquid level determine the water flow of solar heat collector. The fuzzy control structure of solar energy water supplement is shown in figure 3. 


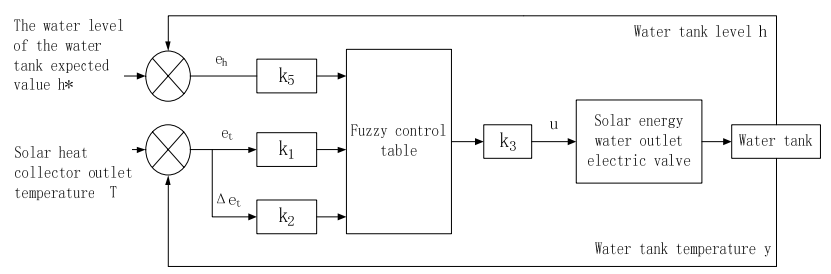

Fig.3. Structure of solar energy make-up water fuzzy control

In Figure 3,the level difference eh, temperature difference et., temperature difference change quantity $\Delta$ et are selected as the input of fuzzy controller. And do scale transformation to them from $\mathrm{x} \in[\mathrm{a}, \mathrm{b}]$ to $\mathrm{x}^{\prime} \in[-6,6]$, so that fall into the common used fuzzy control theory domain range of $[-6,6]$. $a$ and $b$ represent the minimum and maximum values of physical reality acquisition value. The expression of the scale transform is:

$$
x^{\prime}=\frac{12}{b-a}\left(x-\frac{a+b}{2}\right)
$$

Because of the weak computing abilityof S7-224XPand the low control precision demand of solar energy water output, the input and output domain are uniformly discretized and then fuzzily apart into five fuzzy subsets namely: PL(positive large) 、 PM( positive middle) 、 ZE(zero) 、 NM(negative middle) and NL(negative little) . And determine the corresponding membership of each fuzzy subset according to the experience.

In the operation of the system, if the water level $h$ of the water tank exceeds the expected value $h^{*}$, the u should output 0 and the solar energy water outlet valve will be closed. That is a rule If $[<\mathrm{eh}=\mathrm{PL}$ or $\mathrm{PM}$ or $\mathrm{ZE}>]$ Then $[\mathrm{u}=$ $Z E]$. According to the experience and debugging, other rules are established as follows.

Close solar controller when there is no temperature difference: $\mathrm{If}[<\mathrm{eh}=\mathrm{NL}$ or $\mathrm{NM}>$ and $<\mathrm{et}=\mathrm{PL}$ or $\mathrm{PM}$ or $\mathrm{ZE}>]$ Then $[\mathrm{u}=\mathrm{ZE}]$ 。When the water replenishment is too fierce that cause the solar collector cooling too fast, the solar energy water outlet valve opening decreases: If $[<\mathrm{eh}=$ $\mathrm{NL}>$ and $<$ et $=\mathrm{NL}>$ and $<\Delta \mathrm{et}=\mathrm{NL}>$ ]Then[ $\mathrm{u}=\mathrm{NM}]$. If the solar energy replenishment ability is strong, the opening replenishment will be large: $\mathrm{If}[<\mathrm{eh}=\mathrm{NL}>$ and $<$ et $=\mathrm{NL}>$ and $<\Delta$ et $=$ ZE or NM or PL or PM $>$ ]Then[u $=$ NL]. If the solar energy replenishment ability is weak, the opening replenishment will be small: $\mathrm{If}[<\mathrm{eh}=\mathrm{NL}$ or $\mathrm{NM}>$ and $<$ et $=\mathrm{NM}>$ ]Then $[\mathrm{u}=\mathrm{NM}]$. If the water tank quickly filled, try hard to absorb the solar heat: If $[<\mathrm{eh}=\mathrm{NM}>$ and $<$ et $=\mathrm{NL}>]$ Then $[\mathrm{u}=\mathrm{NL}]$. Finally, Mamdani method was used to calculate the fuzzy implication relation[5], then obtains the fuzzy control table and store it in the PLC. When the system is running, use this table to control the opening degree of solar energy water outlet valve. In this process, the amount of computation is very little that can meet the real-time requirement of PLC.

\section{B. Heat pump water supplement.}

The heat pump water supplement control's overall energy strategy is: at any moment, set the expectation $\mathrm{h}^{*}$ of solar energy water tank to the highest water level in the water tank to ensure that the solar energy is the replenishment pioneer and solar energy can be exhausted in one day; Arrange the heating time in accordance with the use of heat pump hot water needs of the hotel while avoid the high price electricity time in accordance with the peak and valley price situation.

Typically, the hotel price peak time is 8:00 11:00、 13:00 15:00、18:00 21:00. Electricity in these hours is expensive. $22: 00 \sim 6: 00$ is the valley time of electricity. Electricity price is relatively cheap. Other period is normal price time. Thus, in the night of 18:00 to 21:00, heat pump should not be opened in principle. But the solar energy cannot be used either. According to historical hotel water record, large amount of water is consumed in this period. So the water storage at 21:00 is the least in a day. Thus, the heating cycle is set from 21:00 to the next day's 21:00.

In the low price period of the heating cycle, heat pump supply water to morning target value. The morning target value determines the amount of heat pump water supplement in low price time. If this value is too large, the water tank may be fulfilled when the sunlight is good in the daytime and that will lead to stop the hot water generated by solar energy from entering the water tank. That is against the energy saving principle. If it is in winter, the temperature is low, the heat pump energy efficiency ratio is low and the heat pump morning target value is small, hot water generated by the heat pump cannot get to the highest level point of water tank in the evening at 18:00. So the morning target value need to be set by user or by the host computer according to the weather information through network, and then through the Profibus afferents to the PLC to decide.

In a heating cycle, the water level at 18:00 shall be the highest. Therefore, set the highest expected level at this moment to the highest point of water tank. Thus, in the heating cycle, estimate the heat pump water replenishment capability of the day as follows:

$$
\mathrm{y}=\operatorname{int}\left[\frac{a-b}{t_{1}}\right]
$$

Type: $y$ for the heat pump heating capacity; a is water amount at $5: 00 ; \mathrm{b}$ is water amount at $3: 00 ; \mathrm{t} 1$ is the actual heating time.

The average water amount expected expression is:

$$
\mathrm{z}=\operatorname{int}\left[\mathrm{c}-\mathrm{yt} t_{2}\right]
$$

Type: $\mathrm{z}$ is the water amount expected in normal price time; c is the largest water amount in tank; $t 2$ is the remaining normal price time.

Finally compare the actual water level at that time with the expected value and then decide to start or stop the pump.

In the high price time of the heating cycle, do not open the pump in principle. But to ensure that the water tank can provide enough water, set up a start and stop security line of 
heat pump in a heating cycle. The security line includes the tank expected value in every moment. When the water level is lower than the value, start the pump to heat using electricity in order to produce enough hot water for users.

\section{THE ACTUAL OPERATION SITUATION}

The bathing hot water system designed in this paper has been stably running for a long time in a hotel. In the actual operation of the system process, if the weather had been fine, the water level of tank started to rise from 8:00 to about 15:00, was closed to its maximum value. If the sunlight had been weak, the solar collector's water replenishment capabilities would be very weak and the pump would open in the valley and normal price time to get the tank level up to the maximum value at 6:00. In the evening, large hot water was used for bathing from water tank. The water level reached the lowest in the early morning the next day. The whole bath water system was running as required.

\section{CONCLUSION}

This paper designs a new type of energy-saving bathing hot water system based of fuzzy control. The control system combines solar collectors with air source heat pump to produce hot water for bathing. It is energy saving and environmental protection. It can change the pollution and waste caused by oil fired boiler. At the same time, according to the large water supplement delay characteristics of the solar energy, fuzzy control strategy is adopted. In the actual operation process, the system operates stably, the fluctuation of water level is in expected range and the system is consistent with the on-demand production principle. In addition, the heat pump operation avoids the high price period that saves the electric charge to some extent.

\section{ACKNOWLEDGEMENTS}

The research work was supported by Shanghai Municipal Science and Technology Commission Fund under Grant No. 13111102500

\section{REFERENCES}

[1] Yu Lihua, Ma Guoyuan, Xu Rongbao: Current Status and Development of Low Temperature Air-source Heat Pump. Construction Conserves Energy, Forum Vol. 35-3 (2007), p.54-57

[2] Li Xiang, Ni Long, Jiang Huiming: Research of Energy Efficiency Evaluation Index of Air Source Heat Pump Water Heater. Fluid Machinery.Forum Vol.37-11 (2009), p.69-73

[3] Qin Xinjuan, Yan Jia: Economic Analysis of Air Source Heat Pump Water Heater. China Appliance Technology. Forum Vol.15 (2008), p.54-55

[4] Cai Xingjian: Introduction of Siemens S7-200 PLC, edtied by Beihang University press (2005).

[5] Wang Yonghua: Modern electrical control and the application of PLC Technology, edited by Beihang University press (2003).

[6] Xu Li. Intelligent Control and System, edited by Machine Press(2007).

[7] Tao C W, Taur Jv: Design of fuzzy controllers with adaptive rule insertion. IEEE Transaction on Systems, Man, and Cybernetics, PartB: Cybernetics 1999, 29( 3) : 389 - 397.

[8] Shen Jiaming: Mathematics Method of Fuzzy Assertion in Fuzzy Control. Automation in Petro-chemical Industry. Forum Vol.5 (1994), p.14-18

[9] Fan Guoping, Yao Minghai: The Design of Fuzzy PID Controller. Refrigeration \& Air-condition, Forum Vol.4 (2004), p.5-7 